\title{
Spiking neural network models for memorizing sequences with forward and backward recall David Chik* and Roman Borisyuk
}

\author{
Address: Centre for Theoretical and Computational Neuroscience, University of Plymouth, Plymouth PL4 8AA, UK \\ Email: David Chik* - david.chik@plymouth.ac.uk \\ * Corresponding author
}

from Eighteenth Annual Computational Neuroscience Meeting: CNS*2009

Berlin, Germany. 18-23 July 2009

Published: 13 July 2009

BMC Neuroscience 2009, 10(Supp| I):P2I I doi:I0.I |86/I47|-2202-I0-SI-P2 I I

This abstract is available from: http://www.biomedcentral.com/I47I-2202/I0/SI/P2I I

(c) 2009 Chik and Borisyuk; licensee BioMed Central Ltd.

\section{Introduction}

It has been reported that when a rat reaches the end of a track, the hippocampal place cells, which spike sequentially during the run, can generate spikes in a short time window in the reverse order $[1,2]$. Also, a forward replay has been recorded from the place cells in a short time interval prior to the run [2]. A recently published model [3] uses phases in the theta cycle to code different locations of the rat. A disadvantage of such an approach is that a frequency of the theta rhythm changes in a wide range and it is not clear whether the phase coding can be reliable under condition of the variable theta-frequency. Here, we present an oscillatory neural network model that can memorize sequences by adapting their synaptic weights during the memorization period. The model includes Hodgkin-Huxley type spiking elements arranged in small groups with excitatory and inhibitory connections. These groups can generate a rhythmic activity in the theta range. Excitatory elements in different groups are coupled by plastic excitatory connections. We propose that each group of rhythmic elements includes two subgroups of excitatory neurons. For the first sub-group, the modification of inter-group excitatory connections is according to the Spike Timing Dependent Plasticity (STDP) learning rule and for the second group the modification is according to the anti-STDP learning rule $[3,4]$. Also, these learning rules are adjusted to the cycles of the theta rhythm. This approach allows us to memorize locations in the track during the running stage and replay them in forward order by the first sub-network and in the reverse order by the second sub-network (Figure 1). To initiate forward (backward replay we use a group of neurons corresponding to the beginning (end) of the track. In both cases the duration of replay is short and takes one cycle of the theta rhythm, in accordance with experimental results $[1,2]$.

\section{Acknowledgements}

This work is supported by UK EPSRC (Grant EP/D036364/I).

\section{References}

I. Foster DJ, Wilson MA: Reverse replay of behavioural sequences in hippocampal place cells during the awake state. Nature 2006, 440:680-683.

2. Diba K, Buzsaki G: Forward and reverse hippocampal placecell sequences during ripples. Nature Neuroscience 2007, 10:1241-1242.

3. Koene RA, Hasselmo ME: Reversed and forward buffering of behavioural spike sequences enables retrospective and prospective retrieval in hippocampal regions CA3 and CAI. Neural Networks 2008, 21:276-288.

4. Han VZ, Grant K, Bell CC: Reversible associative depression and nonassociative potentiation at a parallel fiber synapse. Neuron 2000, 27:6I I-622.

5. Rumsey CC, Abbott LF: Synaptic equalization by anti-STDP. Neurocomputing 2004, 58-60:359-364. 


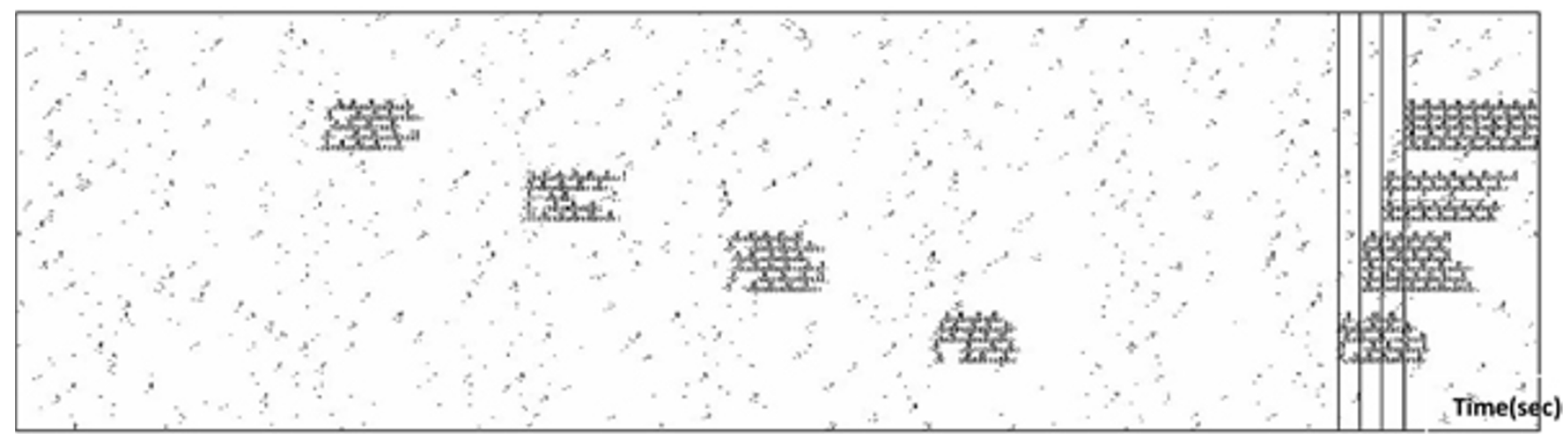

Figure I

Simulations show the memorizing of four activity patterns corresponding to a sequence of four rat positions along the track. Each pattern contains five groups of interactive excitatory and inhibitory neurons. The right part corresponding the time window of $200 \mathrm{msec}$ shows the backward recall initiated by the activity pattern corresponding to the end of the track.

Publish with Bio Med Central and every scientist can read your work free of charge

"BioMed Central will be the most significant development for disseminating the results of biomedical research in our lifetime. "

Sir Paul Nurse, Cancer Research UK

Your research papers will be:

- available free of charge to the entire biomedical community

- peer reviewed and published immediately upon acceptance

- cited in PubMed and archived on PubMed Central

- yours - you keep the copyright 